\title{
La comunicación no verbal en el aula, un análisis en la enseñanza disciplinar*
}

Sandra Shablico **

\section{Resumen}

El objetivo de este fue realizar un estudio sobre el apoyo de la comunicación no verbal en la enseñanza media, con el propósito de obtener elementos de análisis que permitan identificar la fortaleza de estas expresiones para mejorar las prácticas de enseñanza.

En esta investigación la metodología es cualitativa de corte interpretativo; se tomó una muestra de docentes con formación y más de diez años de experiencia. La variedad de la muestra contempló las diferencias del género, las disciplinas formales y fácticas. La recolección de datos se realiza mediante entrevistas semiestructuradas a los docentes, observación participante de clases y un diario de campo.

El análisis de los datos dio lugar a construir categorías teóricas vinculadas con las cualidades de la voz, la gestualidad y la expresividad de las manos y el cuerpo. Estas permitieron interpretar una fortaleza tal que sobrepasa el apoyo no verbal y permite considerarlos como baluartes del docente durante sus prácticas de enseñanza.

PALABRAS CLAVE: comunicación no verbal, enseñanza, docente, gestos, expresión, voz.

\section{Abstract}

The objective of my project was to conduct a study on the support of non-verbal communication in secondary education in order to obtain elements of analysis to identify the power of these expressions to improve teaching practices.

An interpretative qualitative research methodology was used, taking a sample of trained teachers with more than ten years of experience. The sample variety contemplated gender differences, and formal and factual disciplines. Data collection was done through semistructured interviews with teachers, participant observation of classes, and a field diary.

Data analysis led to build theoretical categories related to the qualities of voice projection, gestures, and expressiveness of the hands and body. These categories allowed us to interpret such a strength that exceeds the non-verbal support, and allows the teacher to be considered a bulwark during his or her teaching practices.

KEY WORDS: nonverbal communication, teaching, teacher, gestures, expression, voice.

\section{Introducción}

El lenguaje verbal está dotado de los símbolos necesarios para expresar un mensaje. Sin embargo, normalmente se acompaña de expresiones no verbales que le brindan apoyo, lo ilustran, o, en ocasiones, contradicen lo comunicado verbalmente. 
De La Torre, S. (1984) entiende que el acto didáctico no es otra cosa que un proceso comunicativo, en el que los mensajes no verbales comunican sensaciones, pensamientos y sentimientos expresados singularmente por cada persona, de acuerdo con los significados y símbolos que construye a lo largo de su vida.

Ante estos aspectos y la espontaneidad con que se integra la comunicación no verbal, cabe preguntarse: para la enseñanza, ¿qué lugar ocupa la comunicación?

Mercer (1997) señala desde el constructivismo, la necesidad de atender las representaciones y construcciones efectuadas por los alumnos y analizar sus expresiones no verbales, colaboran para la comprensión de los símbolos construidos en clase.

La motivación que orientó este estudio, ha sido investigar sobre la comunicación no verbal en el aula de enseñanza media, para conocer en primer término si ésta incide en la enseñanza, y en caso afirmativo, dar cuenta de: 1) las fortalezas de su apoyo como medio expresivo para la enseñanza, 2) interpretar la relevancia de los mensajes no verbales metacomunicativos, propiciados por la relación simbólica entre el docente y los alumnos.

En el aula, se articulan expresiones no verbales en forma espontánea. La investigación sobre éstas, permitió visualizar esta modalidad de la comunicación, que en muchas ocasiones la naturalidad con la que se integra la hace parecer invisible. De esta forma, fue posible interpretar si inciden y en qué forma lo hacen.

Este trabajo requirió un marco teórico a través del cual se analizan y vinculan conceptos de autores que han investigado la comunicación no verbal, con otros que abordaron aspectos didácticos. Se consideró a la vez, la evolución del pensamiento del profesorado, integrando las ideas de Kincheloe, J (2001), reconociendo teóricamente algunos aspectos históricos y políticos que pueden haber tenido incidencias en la valoración del lenguaje no verbal en la educación.

\section{Aspectos de la comunicación en el aula}

La etimología de la palabra comunicación, nos conduce a los vocablos latinos "comunis" que significa común. También a "comunicaris": término que se entiende como algo en común con alguien, compartir ideas, información, etc. En este sentido, la comunicación en el aula puede entenderse como el interés del docente y de los alumnos en transmitir pensamientos e ideas, quedando claro el carácter coparticipativo de la acción. Está vinculada, como hecho social, con el comportamiento humano y la interacción de los individuos en sociedad, donde la capacidad simbólica de éstos es la esencia de los actos de comunicación.

\section{El Interaccionismo Simbólico en el aula}

Marta Rizo (2004) señala que esta corriente proporcionó una nueva forma de comprensión de la comunicación. Permite tomar distancia de la visión que la restringe a los medios de información y la ubica centrada en la interacción interpersonal como fundamento de toda relación social:

"[...] la cultura y el aprendizaje humanos se realizan mediante la comunicación, o interacción simbólica, por la que cada ser humano adquiere el propio sentido del ser, su carácter e identidad. [...] Cada situación de interacción se define de acuerdo con el bagaje simbólico que poseemos y que proyectamos in situ, [...]" (Rizo, 2004,15).

En educación, los procesos de enseñanza y los del aprendizaje se concretan mediante el uso de lenguajes y representaciones, accionados en un contexto sociocultural que presenta construcciones simbólicas acordes con fines específicos. 
Comenta Woods, P. $(1998,75)$ "el interaccionismo es interpretativo, se interesa principalmente en cómo ven las personas las cosas, en cómo construyen sus significados". Señala además, que esta interpretación requiere que ambos participantes le concedan el mismo significado a los símbolos utilizados:

"La internalización de símbolos y estructuras de significado, así como estimulación del pensamiento mediante el lenguaje, aumentan el poder reflexivo de las personas [...]" (Woods 1998, 50).

Goffman, E. (1981) propuso un análisis sobre el comportamiento humano en las interacciones cotidianas, que puede trasladarse a la modalidad comunicativa en el aula y las instituciones educativas. Plantea una perspectiva mediante una analogía con la representación teatral. Propone los tipos de interacciones que se generan en ese entorno, como un modelo abstracto para compararlo y analizar los diferentes entornos de la vida cotidiana.

Es interesante analizar las interacciones comunicativas en el aula desde la perspectiva de este autor. Si se aplica su modelo de representación escénica, podemos pensar en los dos grupos humanos interactuando simbólicamente. Dos espacios de acción: uno en el que se ubican el docente y los alumnos actuando bajo las consignas y valores de la institución. Otro: "la región posterior", en el que se encuentran interactuando los docentes, la institución y el currículum bajo los fines de la educación y los valores prevalecientes de la institución.

\section{Pensamiento, lenguaje verbal y no verbal en las interacciones simbólicas del aula}

La educación en el aula de enseñanza media supone situaciones comunicativas y fenómenos colectivos en los que la lingüística, la paraligüística y los aspectos kinésicos son importantes para explorar el modo en que se produce el aprendizaje.

"Todos nuestros sentidos y nuestro cuerpo, emiten y reciben mensajes en intercambio constante." (De La Torre 1984 ,59).

El aula es una estructura psicosocial diseñada con propósitos educativos, donde ocurren eventos sociales y psicológicos como resultado de la interacción docente-alumnos, alumnoalumno, en las que el lenguaje y apoyos no verbales tienen especialmente en el docente, intenciones concretas de generar impacto. En referencia a este aspecto Bruner (1998) plantea:

"La mayoría de nuestros encuentros con el mundo no son, como hemos visto, encuentros directos. [...] Cuando estamos perplejos frente a lo que encontramos, renegociamos su significado de manera que concuerde con lo que creen los que nos rodean." (Bruner 1998, 128).

Acorde con esta idea, el lenguaje y las conductas no verbales del profesor y los estudiantes, son mediadores para el intercambio de información, símbolos y significados que promueven nuevos procesos mentales. De esta dinámica generada por los elementos de la cultura, el pensamiento colectivo y el individual se alimentan procesos del conocimiento.

Vygotsky, L (2000, 130-139) señala que las operaciones psicológicas superiores se generan como consecuencia de la actividad práctica, no como procesos individuales que dependen del desarrollo biológico-evolutivo, sino a través de interacciones sociales. Esta teoría se sustenta en dos aspectos:

1) La relevancia de las relaciones interpersonales.

2) La "zona de desarrollo próximo": una manera de comprender las relaciones entre el aprendizaje y el desarrollo de la actuación educativa. 
En palabras de Vygotsky (2000), la zona de desarrollo próximo, "No es otra cosa que la distancia entre el nivel real de desarrollo, determinado por la capacidad de resolver independientemente un problema, y el nivel de desarrollo potencial, determinado a través de la resolución de un problema bajo la guía de un adulto o en colaboración con otro compañero más capaz" (Vygotsky 2000, 133).

Este autor señala que las interacciones en el aula funcionan como elementos externos de los estudiantes, como organizadores instrumentales que sirven de apoyo para que se produzcan las operaciones internas generadoras de conocimientos. En este proceso de mediación, el lenguaje y sus apoyos no verbales, son vehículos que hacen posible la comunicación; factor imprescindible para los procesos de aprendizaje, los cuales, según Vygotsky (2000) producen en consecuencia el desarrollo evolutivo en el individuo.

En referencia a la zona de desarrollo próximo, Eduardo Martí (2005) señala:

"Vigotsky sostiene que la instrucción crea la zona de desarrollo próximo. Pero esto no significa que la ayuda de otras personas cree, sin más, desarrollo. [...] aviva la actividad del niño, despierta y pone en funcionamiento toda una serie de procesos de desarrollo. Estos son posibles solamente en la esfera de interacción con las personas que rodean al niño y en la colaboración con sus compañeros [...]" (Martí 2005, 74).

En la dinámica de las relaciones interpersonales en un aula, las interacciones verbales del relacionamiento requieren una alternancia entre emisores y receptores acompañados de signos no verbales, que interceden para los turnos del habla, la entonación de las palabras, la mirada, la gestualidad y los movimientos corporales.

La paralingüística, la gestualidad y la kinética, son apoyos valiosos al momento de estructurar los contenidos. Permiten jerarquizar aspectos de éstos, utilizarlos como apoyos de las estrategias de enseñanza y orientar el discurso docente hacia lo que Bruner (1997) denominó como "aprendizaje por descubrimiento".

En referencia a este aspecto del aprendizaje De la Torre (1984) comenta:

"La comunicación no verbal y la creación de situaciones y estímulos van a ser elementos relevantes para un aprendizaje por descubrimiento. En tal dirección resultarán preferibles la aportación de indicios, más que de evidencias." (De la Torre 1984, 56).

\section{Aspectos de la comunicación no verbal}

Las investigaciones de Meharabian, A. (1971, 42-47) sobre los mensajes en actos de comunicación dieron a conocer las siguientes conclusiones:

- el $55 \%$ de un mensaje está integrado por expresiones a través de conductas corporales como la postura, la gestualidad y el contacto visual

- el $38 \%$ por el tono de voz

- el $7 \%$ restante corresponde al contenido del mensaje.

Este autor advierte que los porcentajes pueden variar acorde con las situaciones y el contexto de éstos.

Kendon, A. (1990) señala la relevancia de la comunicación no verbal, en una planificación didáctica preocupada por la formación integral. Entiende que el código verbal resulta insustituible por su alto nivel de estructuración, precisión y simbolización para transmitir mensajes cognoscitivos. Pero afirma también, que no podemos prescindir de otros lenguajes coadyuvantes o subyacentes que refuerzan, completan, sustituyen, e ilustran lo afirmado verbalmente. 


\section{Dimensiones de la comunicación no verbal}

El concepto de la fórmula no verbal es vulnerable frente a distintas connotaciones. Según Mark Knapp (1982) la comunicación no verbal queda delimitada por: "[...] todos los acontecimientos de la comunicación humana que transcienden las palabras dichas o escritas" (Knapp 1982, 41).

Knapp, M. (1982:16-26) distingue 7 áreas de conductas no verbales:

1. Movimiento corporal o cinética, entre los que distingue: emblemas, ilustraciones, expresiones de afecto, reguladores y adaptadores.

2. Características físicas.

3. Comportamientos táctiles.

4. Paralenguaje: cualidades vocales y vocalizaciones.

5. Proxémica.

6. Artefactos.

7. Entorno o medio.

\section{La comunicación no verbal en la enseñanza}

En la actualidad el sistema educativo parte de un concepto clave: el de currículum. Existen en efecto, grandes discrepancias sobre el significado y el valor de términos como enseñanza y currículum. Se han planteado muchos debates abiertos en referencia a lo que los estudiantes deben aprender sobre aspectos de la vida social que han sobrepasado el ámbito de los especialistas en educación.

Desde la visión de Bruner, J. (1997) "la educación no es sólo una tarea técnica de procesamiento de la información bien organizado, ni siquiera sencillamente una cuestión de aplicar 'teorías del aprendizaje' al aula ni de usar los resultados de 'pruebas de rendimiento' centradas en el sujeto. Es una empresa compleja de adaptar una cultura a las necesidades de sus miembros, y de adaptar a sus miembros y sus formas de conocer, a las necesidades de la cultura." (Bruner, J. 1997, 62).

Las instancias de comunicación en su modalidad verbal, deben ser de naturaleza intencional. El docente debe saberlo si se considera que la educación se orienta hacia la formación integral de las personas el desarrollo de capacidades cognitivas, afectivas y de integración social.

\section{Alcance de la comunicación no verbal en el aula}

Eisner, E. (1998) comenta que nuestros sentidos nos habilitan para percibir cualidades del ambiente y actuar haciendo posible la conciencia. Agrega: "[...] la información suministrada por estas capacidades permite la existencia de las imágenes e íconos, a los que solemos referirnos sin mayor reflexión como conceptos." (Eisner 1998, 107).

La preocupación de Eisner por la integración real de la educación artística en el currículum, se encuentra muy bien fundamentada en sus análisis sobre los aportes del arte en la educación para lograr una "cognición ampliada". Su propuesta sobre "la educación de la visión" como una forma más para enriquecer la experiencia formativa de los estudiantes y los fundamentos que manifiesta al respecto, incitan a pensar en la importancia de la comunicación no verbal en el aula.

"El aprendizaje visual representa una forma particular de realización humana que incluye nuestra capacidad de advertir lo que es visualmente sutil y de utilizarlo con una significación personal o social”. (Eisner, 1998,107). 
Uno de los aspectos que motivó esta investigación parte de esta línea de pensamiento. La propuesta de Eisner (1998) representa un posible camino para trascender a la educación tecnicista, rescatando a la vez, el vínculo entre pensamiento y sensibilidad. Su planteo invita a pensar en el lenguaje no verbal del docente, para crear formas visuales que contengan los significados que se desean transmitir y el desarrollo de la capacidad de los alumnos para construir significado desde las formas no verbales de los docentes.

"Cuando las cosas se complican, el lenguaje suele resultar un medio complicado para retener o transmitir la información que uno desea compartir." Eisner, E. (1998,108).

Pensar en comunicación no verbal en el aula implica considerar la capacidad expresiva del cuerpo, la gestualidad y la paraligüística del docente y los alumnos contemplando todos los sentidos humanos: la vista, el oído, el tacto, el olfato y el gusto, como canales para la recepción de mensajes a veces en forma directa y otras apelando a la experiencia sensitiva mediante ejemplos ilustrativos.

Muchos materiales didácticos cuentan con estos apoyos no verbales mediados por la percepción de los sentidos. Cumplen un rol importante al momento de comprender algunos significados que no es posible expresar tan fácilmente a través del lenguaje hablado o del texto.

\section{Lenguaje no verbal - expresión de actitudes en el aula}

Pozo, I. et al (1994), señalan que las actitudes se integran por diferentes componentes que actúan de forma interrelacionada: afectivo (sentimientos y preferencias); cognitivo (conocimientos y creencias); conductual (acciones manifiestas y declaraciones de intenciones).

Pozo, I. et al. $(1994,6)$ comentan también: "Hay muchas formas no verbales de expresar las actitudes (como pueden ser los gestos, los silencios, la no participación o la retirada de una situación, etc.), pero es innegable que, si no contásemos con el lenguaje no verbal, nuestra percepción y nuestro conocimiento de las actitudes se verían muy empobrecidos."

La configuración social del docente, se genera a partir de las propias representaciones sociales sobre su rol, el de sus alumnos y el vínculo con éstos. De acuerdo con las ideas de Jackson, P. (1999) las actitudes del docente, el pensamiento expresado a través del lenguaje verbal y no verbal, no solamente manifiestan, como ya se ha dicho: normas, roles, valores o creencias, sino que además pueden dejar "marcas" en los alumnos, que muchas veces son inconscientes pero pueden quedar siempre presentes.

"Soy portador de marcas del año que pasé con la señora Henzi. [...] Sin embargo, cuando procuro revelar esas marcas, decir cuáles son, ponerlas de manifiesto para que todos puedan verlas, advierto que soy incapaz de hacerlo de un modo que convenza al escéptico, incluso, como debo reconocerlo a la luz de todo lo dicho, al escéptico que hay en mí." (Jackson 1999, 42).

\section{Valor de la empatía en la comunicación y su expresión no verbal en el aula}

Una investigación sobre "La relación maestro-alumno y su relación con el aprendizaje" realizada por Covarruñas, P. y Piña, M.(2004), da cuenta de que el concepto de aprendizaje de los alumnos entrevistados, se sustenta principalmente en habilidades del docente para generar instancias de diálogo orientadas a través de un "vínculo empático". Crear un clima apropiado para pensar críticamente y expresarse.

La comunicación no verbal tiene la potencialidad de ir más allá de las palabras, con mucha velocidad y aportando a la vez, elementos para lograr la empatía necesaria de los procesos de enseñanza. 
“La empatía más alejada del cuerpo, la más abstracta, es aquella que, partiendo de una pizca de lo real, consigue representarse las representaciones del otro. Un relámpago de imagen percibido en otro cuerpo basta para elaborar su psiquismo: sus pensamientos, sus creencias, sus intenciones o sus deseos." (Cyrulnik 2007, 149).

La distancia entre la representación de un concepto y su reformulación orientada por el docente y/o los compañeros caracterizada en la "zona de desarrollo próximo", dependerá del "funcionamiento interpsicológico" tal como Martí (2005) lo interpreta de Vigotsky, específicamente de la interacción con las personas que rodean al alumno.

En estos procesos de comunicación, la empatía del docente y los compañeros, expresada no verbalmente o en apoyo del habla, representa un recurso significativo para el desarrollo de las estrategias de enseñanza que requieran de interacciones comunicativas.

De la Torre (1984) entiende que "La empatía profesor-alumno, de capital importancia para una motivación positiva, se facilita, a juicio de R. Titone, con lenguaje proxémico y paralingüístico. El conocimiento y adecuada utilización de códigos no verbales están llamados a cubrir una dimensión didáctica." (De la Torre, 1984, 57).

En palabras de Cyrulnik (2007, 170): "Aprender a analizar el cuerpo del otro constituye ciertamente un punto de partida fundamental de la comprensión del prójimo." La comunicación no verbal brinda oportunidades para generar espacios de "feedback" de los alumnos. En ocasiones como apoyo al lenguaje hablado, en otras como mensajes no verbales exclusivamente.

"[...] la actividad del alumno, su compromiso, o su manera de atribuir significados a lo que aprende son componentes básicos que explican su aprendizaje.” (Marti 2005, 79).

\section{Valor metafórico de las expresiones no verbales}

A través de la comunicación verbal y la no verbal se construye sentido en el aula. Este proceso encuentra sustento en el lenguaje, en operaciones mentales que conducen a la re-significación de conceptos en términos de otros, y en las metáforas capaces de construir puentes entre los conceptos de partida y los de llegada.

Sin embargo, tal como lo señalan Lakoff, G. y Johnson, M. (1991), las metáforas evidencian un aspecto del concepto, pero ocultan otros que pueden ser parte de la comprensión final, u otros que quizás no sean consistentes con la metáfora y ni siquiera se tenga conciencia.

"[...] la metáfora, impregna la vida cotidiana, no solamente el lenguaje, sino también el pensamiento y la acción.” (Lakoff 1991, 39).

La gran mayoría de las expresiones que cotidianamente utilizamos son en esencia metafóricas. El aula no escapa a esta particularidad, por lo cual la dimensión no verbal de la comunicación está colmada de símbolos que, por sí solos, transmiten mensajes portadores de conceptos, valores, creencias y actitudes del emisor.

\section{La narrativa en la enseñanza: su relación con las expresiones no verbales}

La comunicación no verbal requiere de un análisis más profundo capaz de contemplar la complejidad que caracteriza la vida cotidiana en el aula, dado que puede incidir en el pensamiento para lograr una reflexión que oriente la resignificación de conceptos, promoviendo los procesos que Bruner (1998) entiende como "creación de mundos posibles" en los alumnos.

"El profesor también puede ampliar el tema de un enunciado llevándolo a la especulación y la negociación. [...] Algunos indicadores de actitudes son invitaciones a usar el pensamiento, 
la reflexión, la elaboración, la fantasía” (Bruner 1998,132).

Ya se mencionó que las palabras del docente pueden asumir diferentes significados atendiendo a la entonación, los movimientos, el uso del espacio, las pausas, el volumen de la voz, así como a la gestualidad, la mirada y los movimientos de las manos.

Considerando a la educación como orientadora para la construcción de conocimientos inscritos en una realidad, la paralingüística y la proxémica dan apoyo al lenguaje narrativo del docente, para la creación de diversidad de imágenes que comunican la interpretación individual y subjetiva del narrador.

"El lenguaje impone necesariamente una perspectiva en la cual se ven las cosas y una actitud hacia lo que miramos. No es sólo que el medio es el mensaje. El mensaje en sí puede crear la realidad que el mensaje encarna y predisponer a aquellos quienes lo oyen, a pensar de un modo particular respecto a él" (Bruner 1998,127).

No es posible concebir a la enseñanza sin que el docente exprese actitudes ante los contenidos. Tal como lo señala Bruner (1998), el lenguaje "Debe expresar las actitudes y debe invitar a la contraactitud y en ese proceso dejar margen para la reflexión, para la metacognición" (Bruner, 1998, 134).

Autores como Jackson (1998), Egan (1997), Huberman (1996) y Mc.Ewan (1998) entre otros que también se han ocupado de distintos aspectos de la narrativa, han logrado comprender y transmitir el valor de esta estrategia para la educación, permitiendo a la vez, considerar algunos obstáculos como escenarios para la investigación educativa.

Vinculando estos aspectos con la propuesta de Philippe Meirieu (1992), la comunicación verbal y no verbal a través de la narrativa, es una de las estrategias mediante las cuales se establece "la relación pedagógica" en la que triangulan el deseo de saber, las relaciones en el aula y la mediación del docente.

"Lo que moviliza a un alumno, lo que lo inicia en un aprendizaje, le permite asumir las dificultades, incluso las pruebas, es el deseo de saber y la voluntad de conocer" (Meirieu 1992, 94).

Este autor propone a los educadores una estrategia clara para provocar el deseo de saber mediante la creación de enigmas: "decir o enseñar lo suficiente a fin de que se entrevea el interés de lo que se dice, así como su riqueza, y callarse a tiempo para despertar interés por el descubrimiento" (Meirieu 1992, 101).

La narrativa del profesor encuentra apoyo en la retroalimentación de los alumnos, dado que representa un indicador capaz de revelar si la comunicación global está realmente guiando los procesos necesarios para la apropiación de conocimientos. Los espacios para la expresión de los alumnos, representan instancias en las que el docente, acorde con las ideas de Meirieu (1992) tiene la posibilidad de relevar representaciones, recabar datos imprescindibles en los cuales fundamentará su práctica de enseñanza.

En el aula, escenario de interacciones, el docente debe propiciar un intercambio permanente de pensamientos y expresiones verbales y no verbales. Apoyándose en las ideas de Gardner (1993), Litwin, E. (1997) señala que el apoyo en la comunicación es imprescindible para "[...] reconocer que los estudiantes difieren en la manera de acceder al conocimiento en términos de intereses y estilos". De esta forma el docente tiene la posibilidad de ofrecer a los estudiantes "puertas de entrada diferentes que inicien el proceso del conocimiento" (Litwin 1997, 56). 
La expresión de gestos, tonos de voz y posturas corporales, son portadores de mensajes en sí mismos y como apoyo al lenguaje hablado son una "ventana abierta del pensamiento" (Vygotsky, 1995).

El significado de las palabras es un fenómeno del pensamiento sólo en la medida en que el pensamiento se materializa en el habla, y es un fenómeno del habla sólo en la medida en que el habla se conecta con el pensamiento y es iluminado por él." (Vygotsky 1995,198).

Según Sinclair, J. y Coulthard, M. (1975 Citados en Gabbiani, 2007, 196) en el aula se genera una distribución de turnos de habla específica, que difiere con la estructura que se da en conversaciones espontáneas: la organización de los turnos en el salón es en tres movimientos, y la de conversaciones espontáneas en dos.

Al respecto Gabbiani (2007) comenta que la organización tripartita del aula, conocida como IRF (iniciación, respuesta y "feedback"), el primer y tercer turno son desarrollados por el docente, y el segundo por los alumnos. De esta forma el docente puede controlar las intervenciones de los alumnos y contemplar al mismo tiempo, representaciones de éstos "como parte del andamiaje (en términos de Bruner) que los docentes proveen [...]” (Gabbiani 2007, 196).

De esta forma, la comunicación no verbal ofrece recursos valiosos para la interpretación de elementos culturales y otros valores propios del entorno; colaboran en hacer más "visible lo invisible".

"Para entender el mundo, ya no basta con percibir lo que es, también hay que adivinar lo qué pasa en el invisible mundo mental de los demás" (Cyrulnik 2007, 149).

Tal como señala Pozo (2001), los procesos cognitivos requieren considerar: el contenido, la conciencia y la cultura; las tres $\mathrm{C}$ de la psicología cognitiva, sin las cuales sería muy poco humana. "Debemos situar a la mente, más allá del pensamiento de información, entre el mundo, la conciencia y la carne.” (Pozo 2001, 107).

Reflexionando sobre este punto de vista, el cuerpo es el mediador para percibir y expresar a través de la comunicación, la cual utiliza símbolos lingüísticos que manifiestan el pensamiento a través del lenguaje verbal y corporal.

Tal como lo señala Pozo, I (2001), "Los seres humanos somos lectores excepcionalmente eficaces de emociones [...] La dificultad de controlar esas expresiones emocionales es una prueba de su profundo arraigo corporal, de su vinculación a la mente encarnada e implícita [...]" (Pozo 2001,120).

\section{Metodología}

Como se ha mencionado, la comunicación no verbal en el contexto del aula es parte del proceso comunicativo y no cuenta con una codificación preestablecida. Esta particularidad, hace que cada profesor construya significados distintos a medida que le va dando sentido a sus experiencias interactivas.

Esta característica fue uno de los puntos de partida para definir una orientación metodológica bajo las perspectivas del paradigma constructivista. Acorde con la caracterización de Crabtree

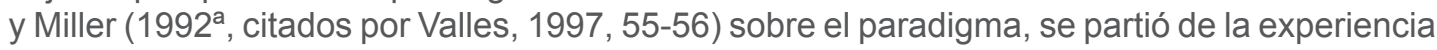
de los sujetos interpretada en su contexto y contemplando diversos puntos de vista implicados, sin llegar a concluir en "verdades últimas" 
Considerando los criterios de Guba y Lincoln (1985, citados por Denzin y Lincoln, 1994, 21), la observación de conductas no verbales en el aula en condiciones naturales, le dio un marco al componente ontológico de esta investigación cualitativa, dado que se observaron realidades múltiples y subjetivas.

\section{Determinación de la muestra}

La investigación se realizó mediante un muestreo intencional, para el cual se tuvieron en cuenta los criterios de "heterogeneidad y accesibilidad" Valles M. (1997, 91) Los actores involucrados fueron docentes con formación específica (Profesorado), que cuenten con diez años de experiencia como mínimo.

Atendiendo salvaguardar la heterogeneidad de la muestra, el grupo de docentes se conformó contemplando las variedades de género y asignatura, con la intención de ampliar el espectro de los datos recolectados según criterios específicos. Con referencia a las asignaturas, se optó por algunos docentes vinculados a la enseñanza de ciencias formales y otros a la de ciencias fácticas.

Acorde con evidencias teóricas las diferencias de expresiones no verbales entre individuos de distinto género fueron contempladas en el diseño de la muestra, con la intención de interpretar si estas inciden, de alguna forma, en la calidad del apoyo brindado para la comunicación de los mensajes.

La variedad de disciplinas integrada al diseño de la muestra, contempló los obstáculos y dificultades definidos por Socas (2000) para el aprendizaje de las ciencias que manejan sistemas de signos abstractos.

Para la identificación de perfiles de la muestra se optó por un "Esquema conceptual general" con una estructura de ejes básicos, similar al propuesto por Glaser y Strauss (1967, citados por Valles, 1997, 93). El "casillero tipológico" resultante, fue utilizado como herramienta de carácter instrumental para la heterogeneidad de la muestra.

A continuación se presenta el casillero tipológico basado en el esquema conceptual propuesto por Glaser y Strauss (1967) que determinó el diseño de la muestra.

Cuadro $n^{0}$ 1. Casillero tipológico para la determinación de la muestra.

\begin{tabular}{|c|c|c|c|}
\hline \multirow{4}{*}{$\begin{array}{c}\text { VARIEDAD } \\
\text { DE } \\
\text { DISCIPLINAS } \\
\text { DE } \\
\text { ENSEÑANZA }\end{array}$} & & \multicolumn{2}{|c|}{ VARIEDAD DE GÉNERO } \\
\hline & & Femenino & Masculino \\
\hline & Cs. Formales & $\begin{array}{l}\text { Docente de } \\
\text { Matemática }\end{array}$ & $\begin{array}{l}\text { Docente de } \\
\text { Matemática }\end{array}$ \\
\hline & Cs. Fácticas & $\begin{array}{l}\text { Docente de } \\
\text { Biología }\end{array}$ & $\begin{array}{l}\text { Docente de } \\
\text { Historia }\end{array}$ \\
\hline
\end{tabular}

Sin embargo, por tratarse de una investigación cualitativa, tal como lo sugieren Miles y Huberman (1994 citados por Valles, 1997, 93-94) no se descartó que la muestra pudiera evolucionar y cambiar, una vez comenzado el trabajo de campo.

\section{Contexto}

La selección del contexto que involucró al objeto de la investigación quedó definida en la determinación del tema. Si bien en la enseñanza primaria y terciaria este tema también merece atención, la definición del contexto contempló algunos criterios mencionados por Valles M. (1997) 
sobre los "estudios de diseños emergentes". La reducción del contexto y de los casos respondió principalmente al tiempo disponible para las restantes etapas del proceso de investigación.

Las tareas de campo de la investigación se llevaron a cabo en dos institutos de enseñanza: uno público y otro privado. Cada uno está ubicado en distintas zonas geográficas de Montevideo con distintos niveles socioeconómicos y culturales.

\section{Estrategia cualitativa}

La naturaleza cualitativa de esta investigación y el análisis de las interpretaciones de los docentes actuando en el sistema de interacciones sociales del aula, requirieron técnicas muy precisas para reunir los datos necesarios y la evidencia empírica que permitió realizar un análisis capaz de trascender la narración descriptiva de éstos.

Se realiza una triangulación de los datos obtenidos a través de la aplicación de las técnicas utilizadas para llevar a cabo las tareas de campo. Esta triangulación, permitió vincular los significados sobre el tema construidos por los docentes, con los registros de las observaciones de clases, como también con las apreciaciones personales que son registradas a lo largo de los procesos. El uso de técnicas distintas y la triangulación de los datos recabados, colaboraron para minimizar las posibilidades de sesgo que pueden ocurrir si se utiliza una sola técnica.

\section{Técnicas para la recolección de datos}

La elección de las técnicas utilizadas para las tareas de campo atiende los objetivos de la investigación y las valoraciones sobre la comunicación y educación como fuentes de información en la construcción del marco teórico.

El análisis de las interpretaciones de los docentes sobre la comunicación no verbal en sus prácticas de enseñanza sigue un proceso empírico para conocer la realidad. Require de técnicas a través de la cuales es posible identificar los tipos de expresiones no verbales utilizados por los docentes, como también para obtener datos sobre los diferentes significados construidos por los profesores.

La selección de técnicas y la planificación previa para la aplicación de éstas, fueron realizadas desde la mirada del paradigma constructivista, y la modalidad cualitativa de investigación, integra las dimensiones sobre la comunicación no verbal, presentadas por Knapp, M. (1982) para el estudio y comprensión del tema.

Las técnicas utilizadas fueron las siguientes:

\section{Entrevistas semiestructuradas}

Acorde con el criterio de Benadiba y Plotinsky (2001 citados por Sautú 2005) las entrevistas son utilizadas como técnicas por brindar la posibilidad de mantener una "conversación sistematizada" para lograr rescatar y registrar experiencias de vida de los docentes con referencia al tema investigado.

Las entrevistas son semiestructuradas; ofrecen en primera instancia dos citas breves de diferentes autores que permitieron conocer las representaciones generales del tema en el orden social fuera del aula. Luego se continúa con preguntas abiertas que contemplan las dimensiones de estudio de la comunicación no verbal utilizadas por Knapp, M. (1982). 


\section{Observación participante}

A través de esta técnica se contemplan en forma sistemática las instancias didácticas promovidas por la comunicación en el aula, atendiendo especialmente los apoyos brindados por la comunicación no verbal para la enseñanza.

En la medida que avanzan las observaciones de clases, es posible priorizar sobre algunos de los aspectos contemplados según una guía de observación diseñada previamente. No obstante, también se atendie especialmente algunos momentos y expresiones no verbales, "insights emergentes" en palabras de Maxwell, J. (1996), que no habían sido contemplados en el diseño previo.

Otro de los aspectos integrados luego de iniciadas las observaciones fue una escala descriptiva sobre la percepción para categorizar y registrar la intensidad expresiva utilizada por los docentes es decir, una valoración en tres niveles, para señalar si la expresión no verbal observada fue leve, normal o intensa.

La observación de clases se apoya de una grabadora digital para el respaldo de aspectos no verbales vinculados con la paralingüística como también, para la ubicación de momentos en que suceden otros tipos de expresiones no verbales observadas y registradas durante las clases. Para esto, los registros de estas conductas no verbales, se complementan con la anotación de dos o tres palabras enunciadas por el docente en el momento de la expresión no verbal. Esta técnica para la recolección de datos permite integrar estos registros en las transcripciones de las clases grabadas.

\section{Diario de campo}

En el diario de campo se registran todas las interpretaciones sobre el tema:

- las vinculadas con particularidades personales de los docentes observados durante las entrevistas,

- expresiones no verbales previstas y las inesperadas que surgen durante las clases,

- apreciaciones generales sobre el clima de la clase,

- condiciones físicas del instituto y del salón.

La lista de datos proporcionada por esta técnica es numerosa y variada. 


\section{Procesamiento de datos}

Se lleva a cabo mediante la desgrabación de las entrevistas a los docentes y las clases observadas que fueron grabadas.

La última etapa del procesamiento de los datos recabados contó con el apoyo informático asistido a través del software Atlas/ti®. Con este recurso se administran todos los documentos generados a partir de la desgrabación de las entrevistas y las clases observadas como también los datos registrados en el diario de campo.

Esta administración conjunta de los documentos es útil para clasificar citas de éstos y vincularlas con códigos creados contemplando algunos de los ejes temáticos presentados por Knapp, M. (1982) para abordar el estudio de la comunicación no verbal.

\section{Análisis de los datos}

A través de la codificación realizada mediante Atlas/ti® se genera la triangulación de los datos obtenidos en el campo. Una herramienta eficaz para analizar en profundidad la recurrencia de expresiones no verbales consideradas como evidencias en el momento de analizar los datos.

Gráfica ำ1. Realizada a partir de un reporte cuantitativo de Atlas/ti® para analizar la recurrencia de las expresiones no verbales observadas

Cantidad de

expresiones no

verbales observadas

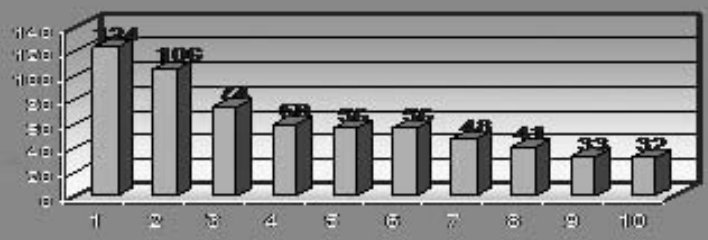

\begin{tabular}{|l|l|l|l|l|l|l|l|l|l|}
\hline 1 & 2 & 3 & 4 & 5 & 6 & 7 & 8 & 9 & 10 \\
\hline $\begin{array}{l}\text { Variación } \\
\text { de } \\
\text { cualidades } \\
\text { de la voz }\end{array}$ & $\begin{array}{l}\text { Uso las } \\
\text { manos }\end{array}$ & $\begin{array}{l}\text { Para } \\
\text { apoyar } \\
\text { aciertos }\end{array}$ & $\begin{array}{l}\text { Para dar } \\
\text { la palabra }\end{array}$ & $\begin{array}{l}\text { Uso de } \\
\text { movimientos } \\
\text { y posturas } \\
\text { corporales }\end{array}$ & $\begin{array}{l}\text { Uso de la } \\
\text { gestualidad }\end{array}$ & $\begin{array}{l}\text { Variación } \\
\text { de la voz } \\
\text { y pausas } \\
\text { para } \\
\text { plantear } \\
\text { enigmas }\end{array}$ & $\begin{array}{l}\text { Gestos y } \\
\text { actitudes } \\
\text { de los } \\
\text { alumnos } \\
\text { que } \\
\text { comunican } \\
\text { mensajes }\end{array}$ & $\begin{array}{l}\text { Para } \\
\text { señalar } \\
\text { errores }\end{array}$ & $\begin{array}{l}\text { Para } \\
\text { manifestar } \\
\text { afecto- } \\
\text { incremento } \\
\text { de } \\
\text { motivación }\end{array}$ \\
\hline
\end{tabular}


Tabla № 2. Relación cuantitativa entre la cantidad de expresiones no verbales de los docentes y las observadas en sus alumnos

\begin{tabular}{|l|l|l|l|l|}
\hline & $\begin{array}{l}\text { Femenino } \\
\text { Biología }\end{array}$ & $\begin{array}{l}\text { Masculino } \\
\text { Matemática }\end{array}$ & $\begin{array}{l}\text { Femenino } \\
\text { Matemática }\end{array}$ & $\begin{array}{l}\text { Masculino } \\
\text { Historia }\end{array}$ \\
\hline Variación de cualidades de la voz & 43 & 22 & 17 & 37 \\
\hline Uso de las manos & 32 & 21 & 22 & 25 \\
\hline Para apoyar aciertos & 24 & 14 & 15 & 21 \\
\hline Para dar la palabra & 16 & 18 & 17 & 8 \\
\hline Uso de movimientos y posturas corporales & 18 & 13 & 14 & 5 \\
\hline Uso de la gestualidad & 30 & 9 & 11 & 5 \\
\hline Variación de la voz y pausas para plantear enigmas & 18 & 12 & 11 & 7 \\
\hline Para señalar errores & 10 & 17 & 5 & 1 \\
\hline Para manifestar afecto/incremento de motivación & 17 & 7 & 7 & 1 \\
\hline TOTAL DE EXPRESIONES NO VERBALES & 208 & 133 & & 110 \\
\hline & & & & \\
\hline Mensajes no verbales de alumnos (gestos, voz, manos) & 16 & 10 & 5 & 2 \\
\hline
\end{tabular}

Gráfica №2. Realizado a partir de la tabla 2 para el análisis cuantitativo entre la cantidad de expresiones no verbales de los docentes y las observadas en sus alumnos.

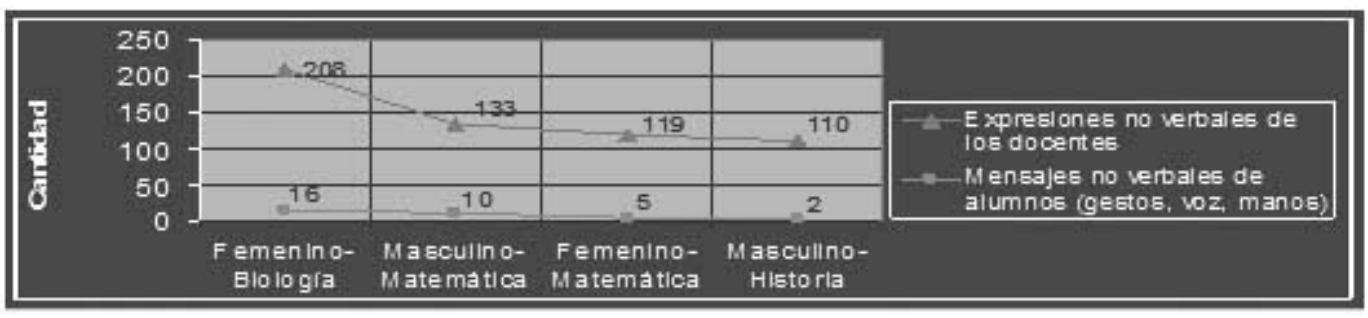

La dinámica generada al vincular las distintas interpretaciones de los docentes con interacciones comunicativas observadas durante las clases, junto con las percepciones personales registradas en estos momentos, son los puntos de partida para construir nuevas interpretaciones que permitieron avanzar en el conocimiento sobre el tema.

Los apoyos no verbales de los docentes encontrados en las tareas de campo son presentados como escenarios de observación y categorías, agrupados según su medio expresivo en torno a los siguientes ejes temáticos:

Las cualidades de la voz.

La gestualidad.

Las manos y el cuerpo.

Metacomunicación en las expresiones no verbales.

Análisis de los datos vinculados con las variedades de la muestra.

\section{3.a. Primer eje temático: las cualidades de la voz}

En el ámbito de la educación, la comunicación no verbal dispone de un elemento preponderante que es la voz con sus esencialidades: volumen, tono, velocidad, fluidez, pausas, etc. Vinculados con este canal expresivo, se encontraron apoyos que son utilizados con gran recurrencia. 
A continuación se presentan los hallazgos relacionados con este eje temático:

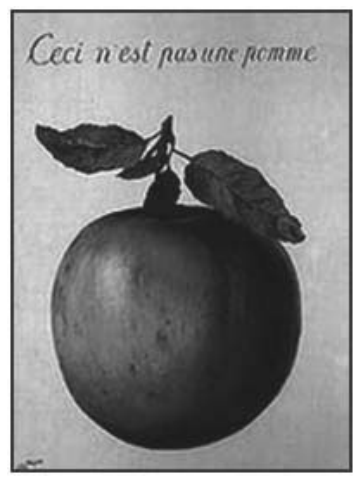

\section{“Esto no es una manzana” René Magritte (1954)}

Con frecuencia los profesores utilizan variaciones marcadas en la entonación y el volumen de la voz para plantear preguntas claves, como también, para la presentación de situaciones en las que es necesario que el alumno realice procesos internos para la construcción de significados.

En estas instancias de comunicación el profesor se apoya en la ductibilidad de su voz, por ser un recurso valioso para generar momentos enigmáticos y en palabras de Meirieu (1992) "hacer del saber un enigma". Ante los conflictos planteados de esta forma, los estudiantes reaccionan de inmediato poniendo en marcha procesos necesarios para el aprendizaje.

No obstante, el apoyo en las variaciones de las cualidades de la voz no es planificado, como así lo señalan los docentes durante las entrevistas. Se trata entonces, de un auxilio comunicativo que natural o artificialmente utilizan los docentes, basándose en sus "conocimientos tácitos" como así los denominó Eisner (2002) para la aplicación de las variaciones de la voz.

De la misma forma que René Magritte (1898-1967) plantea a través del título de su pintura la relación entre la realidad y su representación, la generación de enigmas mediante el apoyo expresivo no verbal utilizado por el docente, es un mediador para plantear cuestionamientos sobre los significados de los alumnos.

En tal sentido, al igual que la afirmación de Magritte "Esto no es una manzana" invita a tomar conciencia sobre la distancia entre el valor representativo de la imagen y la realidad. Los apoyos no verbales para la generación de enigmas son canales expresivos, recursos para actuar en la denominada por Vygotsky (2000) "zona de desarrollo próximo" a través de los cuales el profesor convoca a sus alumnos, mediante la generación de conflictos y enigmas, a reflexionar acerca de sus propias representaciones en función de la interpretación de los significados construidos por el docente.

\section{"Una de cal y otra de arena"}

Los profesores apoyan sus comentarios con expresiones no verbales cada vez que quieren comunicar la aceptación de aportes de los alumnos, como también para señalar los errores. Para esto se valen de intensas expresiones no verbales como variaciones del tono y el volumen de su voz; movimientos con las manos; sonrisas; o movimientos con la cabeza para reforzar elogios o desaprobaciones.

Así como la cal y la arena complementan sus propiedades químicas para formar la mezcla utilizada en la construcción de edificios, el docente mixtura apoyos no verbales para expresar reconocimientos ante los aciertos y señalar los errores para que puedan ser reformulados. De esta forma guía también la construcción de conocimientos de sus alumnos.

Tal como las reacciones entre la cal y la arena son imprescindibles para la cimentación de edificios, la articulación entre los conceptos acertados y los equivocados siempre está presente durante los procesos de construcción de aprendizajes. Los profesores conscientes de esto, se valen de apoyos no verbales para que no pasen inadvertidos. 


\section{Los latidos de la voz}

Todos los docentes afirmaron que utilizan las variaciones de entonación, volumen, ritmo y acentuación de la voz, como apoyo para su enseñanza. A la vez, durante la observación de las clases de estos docentes, éste fue el recurso observado con mayor frecuencia.

Las cualidades de la voz en lo que refiere a su volumen, tono, velocidad, fluidez y pausas, combinadas con frecuencia en un mismo segmento comunicativo, representan un canal para enriquecer los contenidos de los mensajes, de manera muy rápida y precisa en la mayoría de los casos, dado que las variaciones realizadas con la voz traspasan el significado de las palabras en las que se aplican estos matices. A través de ellas los docentes reflejan sus pensamientos, sensaciones y sentimientos que no fueron comunicadas con palabras.

Los profesores señalan que no contemplan el uso de estos apoyos no verbales en la planificación. Sin embargo, el uso es recurrente y utilizado con gran acierto en la mayoría de los casos, dado que se advierten resultados directos, reacciones inmediatas de los alumnos y manifestaciones de los procesos propios del aprendizaje, frente a las variaciones de entonación, volumen o acento de la voz, utilizadas por los docentes.

A través de las cualidades de la voz los docentes expresan variaciones muy sutiles de sus ideas, emociones y sentimientos. Al igual que los latidos del corazón, sensibles a distintos agentes externos e internos que pueden cambian su frecuencia, la voz de los docentes les permite manifestar inmediatamente las "pulsaciones" internas y variarlas en forma rápida y espontánea en la medida que actúan nuevos estímulos, tal como varían los latidos del corazón en respuesta a cada emoción que se presenta.

\section{La ironía totalizada}

El docente de Matemática utiliza con frecuencia un tono irónico para pronunciar palabras que eran opuestas a sus propósitos.

Ejemplo tomado de la observación de una de las clases:

Profesor: -“¿No quieren sentarse un poquito más atrás?”

Alumno: -"Nos queremos alejar."

El tono irónico no solo permitió comprender una intención que no está expresada literalmente sino que además, da lugar a un momento de humor para varios alumnos, que responden inmediatamente con una sonrisa.

La ironía a través de los tonos de la voz va "de la mano" con el humor como recurso didáctico. Es posible vincular esto con las "estrategias de borde" designadas de esta forma por Edith Litwin (2007), para destacar a las prácticas originales, novedosas o también las que resultan divertidas al introducir humor, como una búsqueda de "cursos de acción" con el objetivo de desarrollar contenidos.

\section{3.b. Segundo eje temático: la gestualidad}

En torno a este eje se analizan a continuación los diferentes hallazgos vinculados con la capacidad expresiva gestual pero diferenciados en su contenido. 


\section{Un caleidoscopio expresivo}

La mirada de los docentes es uno de los canales con mayor potencial expresivo para la manifestación de sus propósitos y sentimientos. Es difícil describir con exactitud la gama de miradas observadas, porque la mayoría de las veces se acompañan con otros recursos expresivos como las cejas, la boca y movimientos de la cabeza, lo cual hace que la diversidad sea muy amplia.

Expresan estados de ánimo: curiosidad, asombro, ansiedad, intenciones amistosas y reflexivas a través de su mirada, sin palabras traducen cualidades vinculadas a sus valores personales, como el interés por sus alumnos, la voluntad de enseñar y el grado de sensibilidad entre muchas otras cualidades.

Sin embargo, al consultarle a los profesores sobre la mirada, señalan su importancia como apoyos para la vigilancia de las actitudes de los estudiantes: posturas corporales, gestos, etc. La mirada del profesor que expresa inconformidad con algunas actitudes de los alumnos, es la que surge como resultado de la vigilancia de éstos en la clase, motivada por lo que Foucault (1993) entiende como "control disciplinario".

El docente brinda a través de su mirada una gama rica de expresiones vinculadas con sus intenciones, sensaciones, ideas y sentimientos. Un tipo de expresión desplaza a la anterior en la medida que van variando sus percepciones y sus ideas, las expresiones de la mirada se van transformando como las imágenes al girar un caleidoscopio.

Tal como el movimiento de sus piezas de colores y los rayos de luz sobre los espejos se conjugan para dar una variedad infinita de composiciones, la mirada del docente articula expresiones espontáneas como también intencionales. Una dinámica imposible de prever al igual que las composiciones formadas en un caleidoscopio.

\section{Más que expresiones silenciosas}

En este apartado, como tampoco en los anteriores, la interpretación de aspectos de la comunicación no verbal en apoyo a la enseñanza, no es realizada con la intención de describir o señalar cuáles son los usos aconsejables de la comunicación no verbal. Sería imposible generar un patrón de acciones dado que los entornos educativos no son iguales, ni tampoco las circunstancias comunicativas de la educación.

Menos preciso aun sería generar una lista de apoyos posibles para objetivos afectivos de los docentes, porque su expresión varía con las habilidades expresivas, con aspectos exclusivos del profesor y particularidades de los grupos de alumnos.

Sin embargo, a partir de la observación de clases, es posible valorar momentos en que la sonrisa del profesor asegura la aceptación de los comentarios y las actitudes de los alumnos como también, apreciar los momentos de humor en que los docentes expresan su intención de lograr un clima distendido que facilite el acercamiento a los estudiantes.

Estos apoyos no verbales resultan ser una apertura inmediata del vínculo pedagógico, mediante el que los alumnos perciben y comprenden valores del docente, a la vez que pueden afirmarse pautas para los procesos de aprendizaje. Una sonrisa bien entendida, un momento de humor, puede durar instantes y significar mucho.

Paradójicamente una sonrisa o el humor, pueden reflejar la preocupación de los docentes por brindar mediadores para los procesos de aprendizaje como también, su interés en lograr una comunicación más coloquial. 


\section{Densidad de los silencios}

Los momentos de silencio en la dinámica del aula adquieren significados especiales para los profesores: son portadores de mensajes no verbales de los alumnos sobre el status alcanzado en la construcción de conocimientos.

Sobre este aspecto la profesora de Matemática señaló:

"Cuando los chiquilines están calladitos y no están haciendo nada, como caídos, o están inquietos te das cuenta que están aburridos, o que no les gustó, o que no entienden nada. La actitud del chiquilín que está como atónito no está entendiendo, tiene la mirada perdida."

Ante la ausencia del lenguaje omnipresente, los silencios de los alumnos agudizan los sentidos de los docentes, lo cual les permite captar la densidad del silencio y reaccionar accionando una observación más profunda de sus alumnos, en búsqueda de indicadores no verbales de los estudiantes para captar la "densidad del silencio".

Esta adquiere una significación relevante que los docentes valoran por las posibilidades concretas que ofrece para evaluar su estrategia de enseñanza y en función de esto, tomar decisiones oportunas para accionar cambios estratégicos que les permite brindar una enseñanza adaptada a las necesidades de los procesos de aprendizaje del grupo, en cada momento.

\section{Íconos convocadores}

Las expresiones gestuales que los profesores utilizan para dar la palabra a los alumnos es otro de los apoyos recurrentes. La articulación de este apoyo luego de formular preguntas con una entonación que promueve el enigma, es un ritual para los docentes.

Los gestos para dar la palabra son invitaciones para que los alumnos se expresen; la frecuencia con la que el docente los utiliza y su popularidad, los ha transformado en íconos. La enseñanza los fue integrando a partir de que los docentes comenzaron a comprender que desde el intercambio se reflexiona, se analiza y se construye.

Todos los alumnos comprenden estas voces silenciosas como verdaderos emblemas habituales en la enseñanza de los profesores, expresiones que lindan con lo azaroso y lo intencional pero sin dudas tienen su fuerza y la capacidad de síntesis los transforma en íconos de la enseñanza.

\section{Lo que el espejo nunca refleja}

Al igual que la voz, la gestualidad brinda apoyo a los mensajes en forma espontánea. Sin embargo, existe una diferencia importante entre ambas: el profesor tiene la posibilidad de escuchar las variaciones de su voz, independientemente a que estos matices fluyan espontáneamente, o se trate de un uso premeditado. No ocurre lo mismo con los gestos, el profesor no tiene la posibilidad de observar su gestualidad en el momento de la clase.

Seguramente esta imposibilidad sea la causa de que al momento de opinar sobre los apoyos no verbales para la enseñanza, los profesores reconocen mayor apoyo en las manos y en los tonos de voz que en la gestualidad, exceptuando algunos momentos en que los utilizan en forma premeditada cuando necesitan que los alumnos modifiquen actitudes.

Los docentes reconocen el poder de la gestualidad únicamente con propósitos vinculados a la disciplina, entendida en palabras de Foucault $(1993,141)$ como "métodos que permiten el control minucioso de las operaciones del cuerpo, que garantizan la sujeción constante de sus fuerzas". Foucault, Michel. (1993, 141). 
Los profesores no pueden ver las expresiones de su gestualidad mediante las que expresan o apoyan mensajes vinculados con propósitos cognitivos y afectivos de su enseñanza. Sin embargo, en muchas ocasiones utilizan gestos ilustrativos que no necesitan palabras, en otras canalizan mensajes mediante gestos metafóricos, en los que integran experiencias o circunstancias concretas que los alumnos deben interpretar para comprender la globalidad del mensaje.

\section{3.c. Tercer eje temático: las manos y el cuerpo}

Este eje temático agrupa el análisis de los datos recolectados, que se vinculan con el movimiento del cuerpo y las manos, en función de los apoyos brindados al docente.

\section{Las prolongaciones de la boca}

Este análisis parte de un dato aportado por una de las profesoras informantes a partir del cual se interpretó el nivel teórico alcanzado y le dio nombre a la categoría.

El apoyo en las manos a diferencia de la gestualidad, a pesar de que durante las clases fue observado con menor frecuencia que otros tipos de expresiones no verbales, fue reconocido explícitamente por la mayoría de los docentes entrevistados.

Durante la observación de clases se constataron más de 100 instancias en que el apoyo en los movimientos de las manos es significativo para los propósitos de enseñanza de los docentes. En la gran mayoría de los casos observados, los movimientos de las manos son integrados al momento de pronunciar palabras determinadas de un mensaje, con la finalidad de enfatizarlas.

De esta forma, el apoyo en los movimientos de las manos y el cuerpo ofrece recursos al docente "prolongaciones de su boca" para levantar imágenes en la mente de sus alumnos de manera tal, que a través de estas puedan ver lo que con palabras sería insuficiente. El apoyo de las manos brinda acotaciones a veces más precisas que el alcance de las palabras, favorece la visión de movimientos o posiciones de cuerpos o figuras en el espacio que las palabras no logran visualizar con la misma precisión.

\section{El cuerpo dice lo que omiten las palabras}

Los apoyos no verbales son naturales porque no requieren más que accionar distintas partes expresivas del cuerpo. Su fácil acceso permite que de manera inconsciente o consciente, se utilicen desde el nacimiento con la frecuencia necesaria para lograr habilidades expresivas y la decodificación de los mensajes de otros.

Antes que la palabra, la gestualidad o las cualidades de la voz, el cuerpo se expresa. Desde el inicio al entrar en el salón hasta el final de cada clase observada, los docentes expresan corporalmente actitudes que reflejan pensamientos y sentimientos. No pueden dejar de expresar con su cuerpo, aunque se lo propongan; la inmovilidad también expresa una actitud.

La expresión corporal de los profesores agrega mensajes silenciosos que complementan las palabras o integra significados a las que no son dichas, brindando aportes para la interpretación de los mensajes por parte de sus alumnos. No obstante, el alcance de la expresión corporal no se limita a la emisión de mensajes, también aporta expresiones para brindar un "feedback" silencioso de los mensajes de los alumnos.

Intencionalmente o no, los docentes interactúan en forma permanente aunque no estén presentes las palabras, siempre se comunican porque el cuerpo no puede callarse, al igual que las manos en movimiento, el cuerpo es otra de las prolongaciones de la boca. 


\section{3.d. Cuarto eje temático: Metacomunicación, las expresiones no verbales en la interacción simbólica}

La reflexión sobre la metacomunicación aporta a los docentes elementos para el análisis de sus interacciones comunicativas, orientadas a las prácticas de enseñanza. Esta fue la razón para integrar este aspecto a uno de los objetivos específicos de esta investigación, en la construcción del marco teórico, como también en el diseño de las técnicas para su aplicación en las tareas campo.

Entre los datos recolectados se encontraron apoyos no verbales que fueron agrupados en torno a este eje por interpretarlos como acciones metacomunicativas, que colaboran en las prácticas de enseñanza.

\section{La relación asimétrica expresada en lo no dicho}

La "relación asimétrica" en la cual los estudiantes y los profesores asumen una división de roles y entienden esta asimetría como relaciones de poder (Gabbiani 2007) es expresada por los alumnos y los docentes, valiéndose en muchas ocasiones de los apoyos proporcionados por la paralingüística, la proxémica, la gestualidad y la cinesis. Es el profesor quien normalmente ordena los turnos para hablar y da la palabra a través de un gesto, o indica las acciones que deben realizar los estudiantes valiéndose, únicamente de indicaciones con sus manos, como también utiliza la mirada vigilante que se comentó, para controlar conductas de los alumnos.

En referencia a las relaciones asimétricas es viable interpretar que las expresiones no verbales son utilizadas con distintos propósitos, según las concepciones de cada docente: para afirmar las relaciones asimétricas, o para intentar neutralizarlas.

Mediante una metacomunicación reflexiva los profesores tienen la oportunidad de reconocer la incidencia de lo no dicho en las interacciones asimétricas propias del aula. Tener conciencia de su rol como actor en la comunicación le permite optar por los medios expresivos no verbales que mejor se adapten para su enseñanza y responder oportunamente para brindar una enseñanza adaptada al contexto.

\section{3.e. Quinto eje temático: análisis de los datos vinculados con las variedades de la muestra}

El soporte teórico brindó las pautas para la determinación del diseño de la muestra, el cual integró las variedades de género y tipo de disciplina científica enseñada por cada docente.

Si bien los datos recolectados evidencian algunas diferencias expresivas entre profesores de distinto sexo, el análisis de los datos permite interpretar que estas diferencias, no inciden en la calidad expresiva del apoyo brindado a los procesos de enseñanza. La recurrencia del uso de apoyos no verbales determinados, no responde a las diferencias de los roles de género, sino a las habilidades expresivas de cada docente.

En referencia a la variedad ciencias formales y fácticas, para la enseñanza de las primeras en las cuales los profesores interactúan mediante signos abstractos, los movimientos de las manos resultan imprescindibles y difíciles de sustituir. Durante la observación de las clases de Matemática se advirtieron instancias en que los conceptos fueron abordados por los docentes valiéndose exclusivamente de los movimientos con las manos. 


\section{Conclusiones}

\section{Las expresiones no verbales como baluartes del docente}

Los hallazgos y escenarios de observación han sido presentados como apoyo a las instancias comunicativas orientadas a la enseñanza, y fueron ordenados en torno a los ejes temáticos integrados en el diseño para la aplicación de las técnicas de recolección de datos. No obstante, esta agrupación no restringió la perspectiva del análisis sino que dio lugar a la creatividad para traspasar los límites de esta y alcanzar hallazgos a partir de datos recolectados

Entre las categorías construidas, es importante resaltar la denominada "la densidad de los silencios", por haber sido alcanzada a partir de comentarios de una de las docentes entrevistadas, sin que medie una indagación explícita. Su opinión sobre los silencios de los alumnos, da lugar a que se advierta la relevancia de éstos en los procesos de enseñanza.

Los docentes utilizan apoyos expresivos no verbales en forma combinada. Los integran y articulan de distintas maneras, al mismo tiempo o uno seguido de otro. La gama de combinaciones llevada a cabo por cada docente les otorga un sello expresivo personal que es único.

Esta singularidad está dada por dos criterios de selección que operan casi en forma simultánea, accionados por el docente casi siempre en forma espontánea: 1) selección de un apoyo expresivo, o los que sean necesarios, para brindar la mayor cantidad de elementos de referencia al mensaje que acompañan 2) selección de aquellos que el nivel de habilidades desarrolladas a lo largo de su vida, le permiten sentir mayor confianza en el momento de utilizarlos.

A partir del análisis de los datos es posible interpretar que el aparato fonador, la musculatura de la cara, la del cuerpo para sus posturas y movimientos; las manos, los ojos, los oídos y otros órganos sensoriales, representan recursos importantes para la enseñanza. No sólo por los apoyos expresivos y sensoriales que ofrecen, sino que además, se trata de recursos naturales del profesor: forman parte de su cuerpo, acceden a ellos cada vez que lo necesitan.

Desde su nacimiento las personas utilizan estos recursos expresivos; esta particularidad hace que los docentes dispongan de una vasta experiencia expresiva, superior a la experiencia generada por la aplicación de otros recursos y apoyos para la enseñanza; este aspecto y su efectividad como apoyos para la enseñanza los motiva a utilizarlos con frecuencia.

Los aportes de las distintas disciplinas que se han ocupado de la comunicación, actualmente permiten entenderla como un proceso que no es lineal, dependiente del contexto y los significados construidos por los actores. Las categorías presentadas como resultados de esta investigación permiten avanzar en la comprensión holística de los procesos de comunicación en el aula y consolidar un espacio funcional a las expresiones no verbales, que cuenta con la misma jerarquía que las palabras.

Los hallazgos de esta investigación han brindado pautas para considerar que las expresiones no verbales son baluartes de los docentes para sus prácticas de enseñanza. Esta valoración da lugar al planteo de nuevas interrogantes, que abren el espectro de futuras investigaciones, mediante las cuales indagar acerca de cuáles serían las condiciones y la modalidad necesarias, para la integración del desarrollo de habilidades no verbales de comunicación, en el currículum de formación docente. 


\section{Bibliografía}

Bruner, J. 1997. La educación, puerta de la cultura. Madrid: Visor.

Bruner, J. 1998. Realidad mental y mundos posibles. Barcelona: Gedisa.

Covarruñas, P. y Piña, M. La relación maestro-alumno y su relación con el aprendizaje. Revista: Latinoamericana de Estudios Educativos, [online]. (pp. 47-84) 1er. trimestre, año/Vol. XXXIV, número 001. 2004. [citado 22 de marzo 2012] Disponible en Internet: < http://redalyc. uaemex.mx/src/inicio/ArtPdfRed.jsp?iCve=27034103>

Cyrulnik, B. 2007. De cuerpo y alma. Barcelona: Gedisa.

De la Torre, S. (1984) La comunicación no verbal altera los mensajes recibidos en el aula. En: Enseñanza \& Teaching, [online] (2) pp. 55-66, 1984 [citado 22 de marzo 2012]. Disponible en Internet: <http://campus.usal.es/ revistas_trabajo/index.php/0212-5374/article/ view/3101/3129>

Eisner, E.W. 1998. La escuela que necesitamos. Buenos Aires: Amorrortu.

Foucault, M. 1993. Vigilar y castigar. México: Siglo XXI

Gabbiani, B. Alumno, ¿se nace o se aprende? En: Revista Quehacer Educativo [online] 86 (pp. 194-202) Dic. 2007 [citado 22 de marzo 2012] Disponible en Internet:<http://www. quehacereducativo.edu.uy/docs/171cd30d 86-039.pdf>

Gardner, H. 1993. Inteligencias múltiples. Barcelona: Paidós.

Glaser, B. y Strauss, A. 1967. "The discovery of grounded theory: strategies for qualitative research". Chicago: Pub Aldine.

Goffman, E. 1981. La presentación de la persona en la vida cotidiana. Buenos Aires: Amorrortu.

Guba, E.G., Lincoln, Y. S.: “Competing Paradigms in Qualitative Research”[online] En: Denzin, N. K., Lincoln, Y. S. (eds.). 1994. "Handbook of Qualitative Research"S Sage Publications, California. [citado 22 de marzo 2012] Disponible en Internet:< http://www.ceil-piette.gov.ar/ docfor/docpos/materias/08cualitativa/>

Huberman, S. 1996. Cómo aprenden los que enseñan. Buenos Aires: Aique

Jackson, P. W. 1999. Enseñanzas implícitas. Buenos Aires: Paidós.

Kendom, A. 1990. La realización de la interacción: los patrones de conducta centrada en los encuentros. Cambridge: Cambridge University Press.

Kincheloe, J. L. 2001. Hacia una revisión crítica del pensamiento docente. Barcelona: Octaedro.

Knapp, M. 1982. La comunicación no verbal. Barcelona: Paidós.

Lakoff, G.; Johnson, M. 1991. 2da.ed. Metáforas de la vida cotidiana. Madrid: Cátedra.

LITWIN, E. 1997. Las configuraciones didácticas. Buenos Aires: Paidós.

Martí, E. (c) 2005._Desarrollo, cultura y educación. Buenos Aires: Amorrortu.

MAXWELL, Joseph. "Methods: what will you actually do?" [online] En MAXWELL, J. 1996. "Qualitative research design. An interactive approach". United States of America: Sage Publications. [citado 22 de marzo de 2012] Disponible en Internet:< http://www.ceil-piette.gov. ar/docfor/docpos/materias/08cualitativa/>

Mcewan, H. y Egan, K.; comp. 1998. La narrativa en la enseñanza, el aprendizaje y la investigación. Buenos Aires: Amorrortu.

Mehrabian, A. 1971. "Silent messages". Belmont California: Wadsworth. 
Mercer, N. 1997. La construcción guiada del conocimiento. Barcelona: Paidós.

Meirieu, P. 1992. Aprender, sí. Pero ¿cómo? París: Octaedro.

Pozo, I. 2001. Humana mente. Madrid: Morata.

Pozo, I.; COLL, Cesar; SANABRIA, Bernabé; VALLS, Enric. 1994_Los contenidos de la reforma. 2da.ed. [online] Editorial Santillana [citado 22 de marzo 2012] Disponible en Internet: <http://www.terras.edu.ar/aula/cursos/15/biblio/15COLL-Cesar-POZO-Ignacio-y-Otros-LasActitudes-conceptualizaciones-y-su-inclusion-en-los-nuevos-curriculos.pdf>

Rizo, M. El interaccionismo simbólico y la Escuela de Palo Alto. Hacia un nuevo concepto de comunicación. En: Portal de la comunicación. Aula abierta. . [online] 2004. [citado 22 de marzo 2012] Disponible en Internet: <http:// http://www.portalcomunicacio.com/download/17. pdf $>$

Sautú, R. Boniolo, P., Dalle, P. y Elbert R. 2005. Manual de metodología. Buenos Aires: Clacso. SOCAS, Martín (2000). Dificultades, obstáculos y errores en el aprendizaje de las matemáticas en Educación Secundaria. En: RICO, Luis (coord.) La educación matemática en la Enseñanza Secundaria. Barcelona: Horsori.

Valles, M. 1997. Técnicas Cualitativas de Investigación Social. Madrid: Editorial Síntesis. Vygotsky, L. 1995. Pensamiento y lenguaje. Nueva edición a cargo de Alex Kozulin. Barcelona: Paidós.

Vygotsky, L. 2000. El desarrollo de los procesos psicológicos superiores. Barcelona: Crítica. WOODS, P. 1998. Investigar el arte de la enseñanza. Barcelona: Paidós

\section{Fuentes De Fotografías Y Pinturas}

Figura 1. MAGRITTE, René (1954) "Esto no es una manzana" [pintura] Recuperado de: <http://educacionplasticayvisual. wikispaces.com/El+lenguaje+visual>

${ }^{*}$ Fecha recibido: 02/02/2012

Fecha aceptado: 11/04/2012

**Master en Educación, Universidad ORT Uruguay. Profesora de Educación Media, especialidad Biología, Instituto de Profesores Artigas. Actriz, Escuela Municipal de Arte Dramático "Margarita Xirgu". Docente de Biología y Expresión Corporal. 